\title{
Presence of Acute Chagas Disease Among Febrile Patients in the Western Coast of Mexico
}

\author{
Oscar A. Newton-Sanchez, Valery Melnikov, ${ }^{1}$ Arnulfo H. Nava-Zavala, ${ }^{2-4}$ Maria G. Zavala-Cerna, \\ Carmen Guzman-Bracho, ${ }^{5}$ Ivan Delgado-Enciso, ${ }^{1}$ Fabian Rojas-Larios, ${ }^{1}$ Abril B. Martinez-Rizo, ${ }^{6}$ \\ Uriel A. Lopez-Lemus, and Francisco Espinoza-Gomez ${ }^{1}$
}

\begin{abstract}
Chagas disease $(\mathrm{ChD})$ is a parasitosis caused by the protozoan Trypanosoma cruzi $(\mathrm{Tc})$. It is endemic to almost all Latin American countries, including the southern United States. The acute form of ChD and its actual incidence have rarely been described in Mexico, despite the extensive presence of favorable niches for its transmission. The objective of this study was to estimate the frequency of acute $\mathrm{ChD}$ in febrile patients at the central Pacific coast of Mexico. For this, we surveyed patients with persistent fever (5 to 10 days) in five hospitals at the Mexican states of Jalisco, Colima, and Nayarit in 2012. Samples were taken from a total of 485 patients to detect $\mathrm{Tc}$ in blood using the polymerase chain reaction (PCR) test and direct microscopic examination. Of these subjects, 10 were positive for PCR and none for microscopic examination (2\% in 12 months). We adjusted this rate by the total people at risk in the area and obtained an incidence of 7.4/100,000 habs./year. The positive cases showed no association with sex, rural settlement, or pet ownership, only with the contact with Triatominae insects (odds ratio $=9.22$ and confidence interval: $1.93-44.06$ ). The clinical picture of positive patients showed an association with the diagnosis of lower respiratory tract infections. Meanwhile, only one fatal case showed the typical picture of acute fatal cardiomyopathy. The pulmonary manifestations of our patients suggest possible lung pathogenicity of Tc, which merits further investigation. Our findings differ markedly from the official reports for $\mathrm{ChD}$. This difference suggests an underestimation of the disease. These findings urge the Mexican health authorities to implement more vigorous actions aimed at improving medical skills in the timely diagnosis of $\mathrm{ChD}$, as well as to apply efficient preventive programs.
\end{abstract}

Keywords: incidence, acute Chagas disease, Trypanosoma cruzi, Triatominae, Colima, Mexico, polymerase chain reaction

\section{Introduction}

C Hagas Disease (ChD) or American trypanosomiasis is a parasitosis caused by the hemoflagelated protozoon Trypanosoma cruzi $(\mathrm{Tc})$. It is an infection that, in its natural form, affects wild mammals, usually opossum, armadillos, or raccoons (Yeoa et al. 2005). This parasitosis is exclusive of America, from the south of the United States to Northern Argentina, although at least during the two last decades', worldwide dissemination has been noticed, attributed to human migration (Rassi et al. 2010).
The infection to humans or $\mathrm{ChD}$ denotes a collateral event, although it represents a serious problem of public health. The disease involves three defined phases. The first one is the acquisition of the parasite throughout a cutaneous inoculation by the dejections of the insect vector (Hemiptera, Reduviidae, subfamily Triatominae); throughout blood transfusions (Moncayo 2003); by oral ingestion (ShikanaiYasuda and Barbosa-Carvalho 2012); or by transplacental route (Carlier et al. 2015). ChD is characterized by an acute and a chronic phase of infection. In the acute phase, most patients have the unapparent (asymptomatic) form, while the

\footnotetext{
${ }^{1}$ Laboratory of Public Health, Facultad de Medicina de la Universidad de Colima, Colima, Mexico.

${ }^{2}$ Unidad de Investigación Biomédica Hospital de Especialidades, Centro Médico Nacional de Occidente, Instituto Mexicano del Seguro Social, Guadalajara, Mexico.

${ }^{3}$ Hospital General de Occidente, Secretaria de Salud Jalisco, Zapopan, México.

${ }^{4}$ Facultad de Medicina, Universidad Autónoma de Guadalajara, Zapopan, México.

${ }^{5}$ Instituto de Diagnóstico y Referencia Epidemiologicos, de la Secretaria de Salud, Ciudad de México, Mexico.

${ }^{6}$ Laboratorio de Investigación Biomédica, Universidad Autónoma de Nayarit, Tepic, Mexico.
} 
remaining infected individuals usually show a nonspecific febrile disease. In the chronic phase, the illness can show protean clinical manifestations, such like persistent fever, signs of cutaneous inoculation, as the periorbital swelling (Romaña's sign) or local inflammation in any part of the body (inoculation chagoma), as well as a myriad of signs that could be present in this entity, such as cardiomyopathy, cardiac arrhythmias, lymphadenopathy, skin rash, upper respiratory symptoms, hepatosplenomegaly, and diverse neurologic manifestations (Rassi et al. 2010). The diagnosis of Acute $\mathrm{ChD}$, according to current criteria, is established when circulating Tc is documented in patients with clinical suspicion (Pinto Dias et al. 2016, Secretaria de Salud/ Subsecretaría de Prevención y Promoción a la Salud 2019). This last criterion could be quite imprecise since the medical suspicion of $\mathrm{ChD}$ is rarely stated even in endemic countries, where usually there is a severe lack of knowledge by medical staff (Stimpert and Montgomery 2010, Benítez et al. 2013). On the other hand, laboratories seldom perform Tc detection through traditional microscopic examination, and when they do, it has very low sensitivity, the same happens with the use of polymerase chain reaction (PCR) test (Gomes et al. 2009).

After the acute phase, an undetermined or subacute stage of infection ensues, which is generally asymptomatic and can only be detected serologically for anti-Tc IgG (Moncayo 2003). Finally, after a period of 5 to 20 years appears the chronic phase of $\mathrm{ChD}$. In this phase, the disease develops cardiac or digestive complications that frequently evolve to organ failure, and in some cases to death (Pinto Dias et al. 2016). The estimated prevalence of ChD in Latin America ranges from $0.1 \%$ to $4 \%$, with the possible existence of at least 70,199,360 of infected people and an annual mortality of 12,000 per year, the vast majority of them undiagnosed (Pérez-Molina and Molina 2018).

In Mexico, the prevalence, according to a recent metaanalysis, is 3.3\% (Arnal et al. 2019). Despite these figures, the official number of confirmed $\mathrm{ChD}$ has been quite lower than that, although the most recent data show 126 acute cases in 2017 (Alvarez-Hernandez et al. 2018), and 760 chronic patients with 117 acute cases for 2018 (SUIVE/DGE 2018).
Among the riskiest zones for $\mathrm{ChD}$ transmission in Mexico are the states of Veracruz, Chiapas, Oaxaca in the South, as well the states of Jalisco and Nayarit, at the central western coast (SUIVE/DGE 2018, Arnal et al. 2019). In this former region, there are high rates of infestation with Triatomines (Triatominae colonization index), mainly Triatoma pallidipennis (Stål) and $T$ longipennis (Usinger), associated with human settlements representing risk niches to the transmission of ChD (Ramsey et al. 2015), as well as significant rate of natural infection of Triatominae with Tc (Martinez-Ibarra et al. 2008). In this study, we performed a longitudinal study on the western coast of Mexico during a year, to detect the frequency of Tc parasitemia among patients attending public hospitals, complaining of fever lasting for more than 1 week, using PCR technique, as well as microscopic examination of blood to identify Tc in blood.

\section{Materials and Methods}

\section{Target population}

The study involved urban and rural populations at hospital level in the coastal areas of the states of Jalisco, Colima, and Nayarit in western Mexico. The studied region is a strip located between $103^{\circ} 33^{\prime} 08^{\prime \prime} \mathrm{W}-19^{\circ} 02^{\prime} 02^{\prime \prime} \mathrm{N}$ at the north, up to $103^{\circ} 42^{\prime} 36^{\prime \prime} \mathrm{W}-18^{\circ} 40^{\prime} 51^{\prime \prime} \mathrm{N}$ " to the south, with an approximate area of $6400 \mathrm{~km}^{2}$. The region involved 89 municipalities with a total population of 2,683,900 inhabitants (INEGI 2015), (see map in Fig. 1) most of them living in the urban areas of Puerto Vallarta in Jalisco and the city of Colima and Tepic in Nayarit (this involved 1,140,000 habitants.), while $\sim 1,544,000$ live in small cities $(<50,000)$, or in rural settlements $(<5000)$. We carried out the study in patients who came to medical attention in the emergency room of hospitals belonging to the Health Secretariat of Tepic, Nayarit; city of Colima and Manzanillo, in Colima state; and Puerto Vallarta and Ciudad Guzmán, in Jalisco (Fig. 1). The study was done along the period from March 2011 to June 2012. During that year, about $1,135,000$ total medical consultations at the 89 municipalities were attended in the studied municipalities, and from these, the 5 participant hospitals attended an

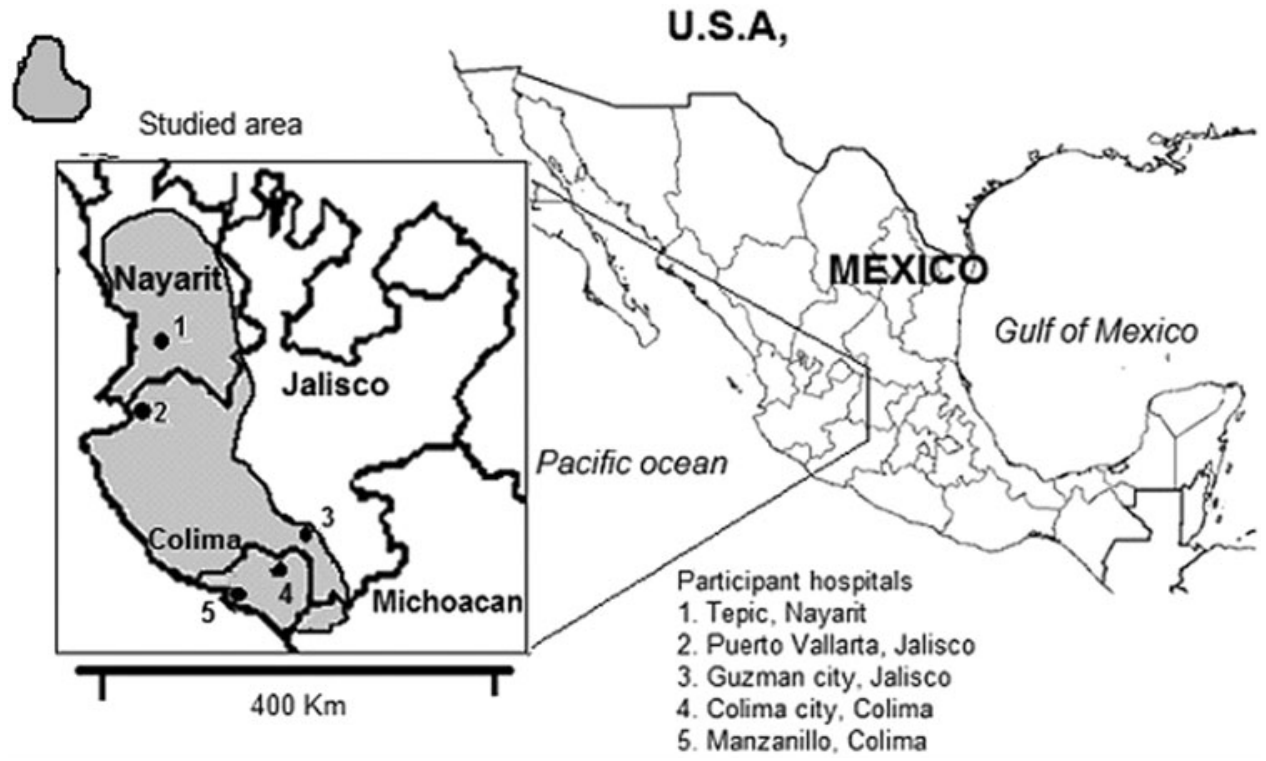

FIG. 1. Map of the studied area in the central Pacific coast of Mexico and the participant hospitals. The shaded area covers the municipalities involved in the study. 
average of 42,000 nonobstetric medical emergencies per year (Secretaria de Salud and Gobierno de Mexico, 2012). If we consider a preliminary survey among those patients who attended at emergency rooms of the mentioned hospitals, which showed that $12 \%$ of them complained of persistent or complicated fever, we estimate a total target population at risk of 5000 .

\section{Inclusion and exclusion criteria}

Four hundred eighty-five patients were selected consecutively, depending on the accessibility to the emergency rooms at each hospital. The inclusion criteria were as follows: fever $\left(>38^{\circ} \mathrm{C}\right.$ ) for 5 to 10 days before admission; age 1 to 80 years; and complete data on residency, history, and clinical diagnosis upon discharge from the emergency room or hospital. Patients with a chronic deteriorating disease (decompensated diabetes mellitus, uremic, cancer, and so on), pregnant women, and immune-deficient subjects were ruled out. As our main objective was to explore the association between Tc parasitemia with clinical diagnosis in patients with a subacute febrile disease, we omitted the presumptive clinical diagnosis of chronic $\mathrm{ChD}$ in patient's selection, except for those cases previously confirmed that served as positive controls. We also excluded cases of chronic fever as tuberculosis, HIV/AIDS, fever of unknown origin, and so on, as well as very acute infections like the common cold, dengue, or other.

\section{Data collection}

We registered sex, age, place of residence, knowledge about Triatomine insects or contact with them, as well as school level, and pet ownership. The treating medical team registered the clinical diagnosis based on clinical, laboratory, and radiological studies.

\section{Laboratory tests for Tc detection}

In each patient, we obtained a $10 \mathrm{~mL}$ blood sample from the antecubital vein, except in children younger than 3 years in whom the personnel extracted only $3 \mathrm{~mL}$. After centrifugation at $5000 \mathrm{rpm}$, in 121 of them, a layer of leukocytes (buffy coat) was collected by the laboratory team for direct fresh (Strout's technique) and extended dry smear stained with the Giemsa technique for microscopic examination, in search of Tc. Two independent observers reviewed these samples. Furthermore, a scanning of each smear with a robotic program for microscope was done (AXioVision 4.8 for Carl Zeiss Axioscope). Along with the microscopic study, we also performed a PCR test for the detection of Tc. For this purpose, a $5 \mathrm{~mL}$ blood subsample was treated with guanidine hydrochloride-EDTA buffer. After thawing the blood samples by adding $200 \mathrm{~mL}$ of a $5 \%$ Chelex solution (Chelex-100; Bio-Rad, Catalog No. 1422832), we centrifuged at $16,500 \mathrm{~g}$ for $1.5 \mathrm{~min}$. The supernatant is transferred to a microcentrifuge tube and centrifuged again at $16,500 \mathrm{~g}$ for $1.5 \mathrm{~min}$. Thereafter, we extracted the DNA using the NucleoSpin ${ }^{\circledR}$ Tissue kit, following the manufacturer's instructions (NucleoSpin 2014) for its later amplification. The primers specific for a sequence encoding a mitochondrial membrane protein segment of Tc according to Gilber et al. (2013), TcZ1 and TcZ2 were: (5'CGAGCTCTTGCCCACACGGGTGCT3' and 5'CCTCCAAGCAGC GGATAGTTCAGG3'). The ex- pected band size was $188 \mathrm{bp}$. For each experiment, a negative blank water control and positive control with a low number of copies (50 copies of the parasite genome) were used. Our team performed PCR tests in triplicate, using a programmable thermal cycler (Mastercycler personal, Eppendorf AG, Germany) in the laboratory of Molecular Biology at the Facultad de Medicina of the Universidad de Colima, Mexico. For external validation, 3 patients officially diagnosed as ChD by the Ministry of Health and 10 newborn children of seronegative mothers also underwent a PCR test.

\section{Ethical and biosafety issues}

All patients signed an informed consent form; in the case of children, the parents signed the form. Our laboratory team performed the blood sampling and blood disposal according to the WHO safety protocols (WHO 2011). The project was reviewed and approved by the Ethics Committee of the Ministry of Health of the States of Colima, Nayarit and Jalisco (number 124-09). We delivered the final results and databases to the Ministry of Health of each state throughout a final report of the project called, "Frequency and spatial distribution of emerging and reemerging infectious diseases in the western part of Mexico," with the support of National Council of Science and Technology (CONACYT). These documents included information about the positive cases and were provided to the Ministry of Health for their follow-up and eventual treatment if $\mathrm{ChD}$ was confirmed.

\section{Statistical analysis}

We calculated the frequency of Tc infection dividing the positive cases/total valid studied individuals. The estimation of crude incidence was then calculated in the population at risk (5000). Subsequently, we extrapolate this rate to the total population that is covered by the hospitals of the Ministry of Health of the involved municipalities (54\%), which corresponds to $\sim 1^{\prime} 501,000$ habitants (INEGI 2015).

The association between positive cases with demographic variables sex, age, schooling, type of locality (rural or urban), pet ownership, and contact with Triatomines was analyzed using logistic regression through the EPIDAT program (2012). For each value, the mean and its 95\% confidence interval (CI) were calculated using the Wald's method. Statistical significance was established with a value of $p<0.05$ for two tails after the Yates adjustment, or if the CIs for odds ratio do not cross the unit.

\section{Results}

The frequency of Tc parasitemia detected by PCR was 10 positive cases of 485 patients in 15 months $=2.06 \%$ (95\% CI: 0.99-3.76). This represents $1.5 \%$ per year in the sampled population. Considering that a total of 5000 patients were referred to hospitals of the Secretary of Health with persistent or complicated fever, an incidence of acute trypanosonemia in this population at risk is of 103 patients per year. If we also consider another 90 patients attended at the Mexican Institute of Social Security, the estimated crude annual incidence in the region could reach around 7.45/100,000 per year.

From the 485 samples, we obtained 121 fresh blood smears, and none resulted positive to Tc, neither by the concentration Strout's method nor throughout the dry stained 
blood smear films. The external validation for PCR test showed that in the four previously confirmed cases of $\mathrm{ChD}$, all were positive for this examination, while negative results were obtained with blank samples and with serum obtained from three newborns of seronegative mothers.

Table 1 shows the demographic characteristics of the patients, as well as the positive case rates for acute $\mathrm{ChD}$ for each variable.

Table 2 shows the clinical diagnosis made by medical staff and their relationship to Tc presence.

In none of the 10 patients with Tc parasitemia, the diagnosis of ChD was suspected, meanwhile of 5 patients with clinical suspicion of $\mathrm{ChD}$, none was positive.

Of the 10 positive cases for blood Tc, a patient was diagnosed with nonspecific fever; another as dengue; 2 more as a common cold; and 3 cases as infection of the lower airway: of the latter, 2 small residents of Villa de Álvarez, Colima, showed a clinical picture of community-acquired pneumonia and another adolescent was diagnosed with asthmatiform bronchitis. Remarkably, two other adult males were diagnosed as probable pulmonary tuberculosis and resulted positive for Tc. Both were sawed at the Hospital Regional de Colima and presented chronic cough, malaise, and persistent fever. The medical report of chest X-ray films mentioned "slight diffuse bilateral haze"; the sputum smear did not yield fast acid bacilli, and both patients left the hospital be- cause of clinical improvement with the use of antibiotics. One from the nine patients with acute carditis resulted positive to Tc by PCR, establishing the diagnosis of truly acute Chagas carditis. This patient, a 36-year-old male from "El Ranchito," Michoacán, a community with high margination index (CONAPO 2009), who reported contact with domestic Triatominae, showed acute cardiac global failure, with biventricular dilatation, pulmonary edema, and a ventricular tachyarrhythmia that finally caused his death at the hospital of Colima with the final official diagnosis of "unspecific cardiomyopathy." Although, in 3 from the 10 positive cases, the patients denied contact with Triatomine, in all the communities where they live, researchers previously reported the presence of peridomestic Triatomine, mainly $T$ longipennis and $T$ pallidipennis (Martinez-Ibarra et al. 2008, Ramsey et al. 2015)

\section{Discussion}

Strictly speaking, only one patient in this study (that who died with acute cardiomyopathy) fulfilled the criteria for Acute ChD diagnosis. However, since its original description, considerable debate has persisted over the diagnosis of $\mathrm{ChD}$, mainly due to the scarce chance to visualize or cultivate the parasite from blood or tissues. Over the time, the detection of antibodies against Tc or its genetic products became

Table 1. Demographic Characteristics of the 485 Subjects Studied at the Emergency Room of Hospitals from Colima, Jalisco, AND Nayarit During 2011 to 2012

\begin{tabular}{|c|c|c|c|c|}
\hline Variable & Total & Tc positive & Rate & OR $(95 \% C I)$ \\
\hline Female & 255 & 4 & 0.0156 & \\
\hline Male & 230 & 6 & 0.026 & $1.68(0.5-5.6)$ \\
\hline \multicolumn{5}{|l|}{ Age (years) } \\
\hline$<5$ & 47 & 2 & 0.042 & \\
\hline $6-10$ & 45 & 0 & 0.00 & \\
\hline $11-20$ & 85 & 3 & 0.035 & \\
\hline $21-30$ & 96 & 0 & 0.00 & \\
\hline $31-40$ & 67 & 2 & 0.029 & \\
\hline $41-50$ & 53 & 0 & 0.00 & \\
\hline $51-60$ & 43 & 2 & 0.046 & \\
\hline $61-70$ & 30 & 0 & 0.00 & \\
\hline$>71$ & 19 & 1 & 0.052 & $1.0(0.9-1.03)$ \\
\hline \multicolumn{5}{|l|}{ Pets at home ${ }^{\mathrm{a}}$} \\
\hline Yes & 224 & 4 & 0.018 & $0.66(0.15-3.01)$ \\
\hline No & 245 & 2 & 0.008 & \\
\hline \multicolumn{5}{|l|}{ Hospital } \\
\hline Colima, Col. & 221 & 7 & 0.031 & Colima vs. the rest of hospitals: \\
\hline Tepic, Nayarit & 147 & 2 & 0.013 & $11.16(1.4-89) p=0.011$ \\
\hline Puerto Vallarta, Jal. & 55 & 0 & 0 & \\
\hline Manzanillo, Col. & 38 & 0 & 0 & \\
\hline Ciudad Guzman, Jal. & 24 & 1 & 0.041 & \\
\hline \multicolumn{5}{|l|}{ Type of locality } \\
\hline Urban & 389 & 8 & 0.02 & $1.0(0.9-1.03)$ \\
\hline Rural & 96 & 2 & 0.02 & \\
\hline \multicolumn{5}{|l|}{ Contact with Triatoma } \\
\hline Yes $^{b}$ & 94 & 7 & 0.074 & $5.6(1.4-22.1)$ \\
\hline No & 212 & 3 & 0.014 & \\
\hline Total & 485 & 10 & 2.06 & $(1.98-2.2)$ \\
\hline
\end{tabular}

${ }^{a}$ Mainly dogs, secondly cats and birds.

${ }^{\mathrm{b}}$ Three hundred and six people recognized the Triatomines in a sample box.

CI, confidence interval; OR, odds ratio; Tc, Trypanosoma cruzi. 
Table 2. Clinical Diagnosis of the 485 Patients, Made by the Medical Staff in Their Discharge FROM EMERGENCY ROOM OR FROM HOSPITALS IN COLIMA, JALISCO, AND NAYARIT DURING 2011 TO 2012

\begin{tabular}{|c|c|c|c|c|}
\hline Diagnosis & $\begin{array}{c}T c \\
\text { negative }\end{array}$ & $\begin{array}{c}T c \\
\text { positive }\end{array}$ & Hospital & Death \\
\hline Unspecific fever & 92 & 1 & 8 & 0 \\
\hline Dengue & 63 & 1 & 11 & 0 \\
\hline Common cold & 54 & 2 & 0 & 0 \\
\hline $\begin{array}{l}\text { Lower respiratory } \\
\text { tract infection }^{\mathbf{a}}\end{array}$ & 51 & 3 & 15 & 3 \\
\hline Pharyngotonsillitis & 49 & 0 & 0 & 0 \\
\hline Urosepsis & 45 & 0 & 6 & 0 \\
\hline Acute gastroenteritis & 21 & 0 & 0 & 0 \\
\hline Inespecific virosis & 15 & 0 & 2 & 0 \\
\hline Seasonal Influenza & 14 & 0 & 4 & 0 \\
\hline $\begin{array}{l}\text { Pulmonary } \\
\text { Tuberculosis }\end{array}$ & 12 & 2 & 4 & 1 \\
\hline Acute cardiopathy ${ }^{\mathrm{b}}$ & 9 & 1 & 8 & 2 \\
\hline Acute appendicitis & 7 & 0 & 7 & 0 \\
\hline Typhoid fever & 7 & 0 & 0 & 0 \\
\hline Probable Chagas & 5 & 0 & 2 & 0 \\
\hline $\begin{array}{l}\text { Miscellaneous } \leq 6 \\
\text { cases: skin } \\
\text { infections (6); } \\
\text { neoplasia (6); } \\
\text { gynecologic sepsis } \\
\text { (6); rheumatic } \\
\text { disease (5); allergy } \\
\text { (4); neurosepsis (3); } \\
\text { hepatitis (3); otitis } \\
\text { (2); liver abscess (2); } \\
\text { HIV (1); brucellosis } \\
\text { (1); malaria (1): } \\
\text { colitis (1) }\end{array}$ & 41 & 0 & 14 & 0 \\
\hline Total & 485 & 10 & 85 & 6 \\
\hline
\end{tabular}

${ }^{a}$ It includes community-acquired pneumonia, acute bronchitis, and bronchiolitis.

${ }^{b}$ Encompasses: acute myocarditis, endocarditis, pericarditis. The patient positive to Tc died.

new tools for definitive diagnosis of $\mathrm{ChD}$, even when the conventional methods show negative results, for example, in congenital or in post-transplantation reactivation of $\mathrm{ChD}$ (Schijman et al. 2000, Diez et al. 2007). Regarding acute $\mathrm{ChD}$, some authors proposed a subclassification as early, intermediate, and late, according to the presence of $\operatorname{IgM}$ Anti-Tc, and anti-Gal $\alpha$ in serum. In the early stages, there is an intense cellular and humoral immune response that could dramatically reduce circulating parasitemia in such a way that only PCR tests can detect the parasite (Antas et al. 1999). So, as almost all of our patients were in the second week of fever, it is feasible to assume that PCR has detected Tc in blood without necessarily having circulating antibodies. Some researchers question the PCR technique for the diagnosis of $\mathrm{ChD}$ since they consider this technique as a no standardized In-House procedure. Nevertheless, recently, an international group carried out a study to validate different protocols for PCR tests in $\mathrm{ChD}$, and they recognized those included in a group named LbD2 (in which our method can be enrolled), as those with better performance in sensitivity and specificity (Schijman et al. 2011). False-positive tests can be caused by contamination during the process, a risk that is reduced by repeated testing, as was done by us. Another cause of false-positive results is an infection by Trypanosoma rangeli or leishmaniasis in humans, both conditions are quite rare in Mexico, so this possibility is very remote in our patients.

On the other hand, many authors have recently recognized the presence of atypical clinical pictures in acute $\mathrm{ChD}$, especially those associated with oral inoculation (Pinto Dias 2016). These researchers warn of the presence of acute ChD among residents of places with Triatomine infestation, who complain of prolonged fever of unclear origin. In this sense, at least $90 \%$ of our patients fulfilled the requirements for acute ChD (Gomes et al. 2009, Secretaria de Salud/ Subsecretaría de Prevención y Promoción a la Salud 2019), so we can assume that at least nine of our patients can be categorized as Acute $\mathrm{ChD}$, and this confirms previous reports of active transmission of $\mathrm{ChD}$ on the western coast of Mexico (Coll-Cardenas et al. 2004, Newton-Sánchez et al. 2018). In contrast to official figures that reported a national incidence of 830 new cases in 2017, indicating a rate of 0.7/100,000 inhabitants (SUIVE/DGE 2018, Secretaria de Salud/Subsecretaría de Prevención y Promoción a la Salud 2019), our present estimate of 7.45 cases $/ 100,000$ inhabitants per year at western coast of Mexico indicates that the governmental data of prevalence and incidence in Mexico could be dramatically underestimated (Arnal et al. 2019). It is possible to assume that there was a casual coincidence of Tc infection with another microorganism; however, taking into account the low sensitivity of the test for chronic infections and, that reports about the prevalence of chronic $\mathrm{ChD}$ by PCR in the field are very scarce (Wincker et al. 1997), it is much more plausible to think that we face real acute $\mathrm{ChD}$. Anyhow, the distinction between acute $\mathrm{ChD}$ or Tc parasitemia is irrelevant, since these subjects must be treated with anti-trypanosomal medications and followed to look for future chagasic complications (Pinto Dias 2016, Pérez-Molina and Molina 2018), independent of other comorbidities.

It is noteworthy that only one patient coming from a marginated rural community, who reported contact with Triatomines, developed a classic clinical picture of acute $\mathrm{ChD}$ with lethal cardiomyopathy, while none of our patients showed signs of inoculation, such as the sign of Romaña or chagomas. On the contrary, a remarkable finding was that most cases showed respiratory symptomatology that lead to the diagnosis of asthmatiform bronchitis, pneumonia, or even pulmonary tuberculosis. These last findings could be associated with the recent discovery in Colima about the striking pulmonary, bronchial, and lung vascular disease observed in animals inoculated with Tc (Melnikov et al. 2005). In this sense, we sought that the development of a chronic damage in the lung could eventually drive to pulmonary hypertension, and explain some cases of pulmonary vascular damage in $\mathrm{ChD}$, not fully explained by the global heart failure (Pereira de Godoy and Batigalia 2000, Singh et al. 2019). This hypothetical chronic lung disease could also explain the findings of predominantly right heart disease in chagasic cardiomyopathy (Nunes et al. 2004). This topic reopens the debate, long since abandoned, on the presence of primary bronchial and pulmonary damage in ChD (Bethlem et al. 1991, Lemle 1999).

The main limitation of the study was the lack of serologic tests for IgG or IgM detection; however, although we did 
not do serologic tests for anti-Tc IgM or anti-Gal $\alpha$ antibodies, we consider that the only presence of parasitemia in patients with subacute fever who reside in communities infested by Triatominae is enough to establish the diagnosis of true Trypanosonemia and admittedly acute ChD. Another limitation was the sampling bias toward the Colima Hospital as the leading collection site, which was caused by the reluctance to collaborate with the project in other medical units in the region..

\section{Conclusions and perspectives}

The finding of a high incidence of Tc infections in the region, especially in Colima, urges the implementation of more intensive programs for the detection and timely prevention of $\mathrm{ChD}$ in all areas where Triatomine insects are in contact with human dwellings. This program should include vigorous training for physicians and the entire health team, as well as the implementation of fast and reliable laboratory tests such as PCR, which until now is only recommended for the detection of Tc in newborns and transplanted patients (Schijman et al. 2000, Diez et al. 2007, Secretaría de Salud/ Subsecretaria de Prevención y Promoción a la Salud 2019). Finally, health authorities in Mexico should accept the challenge of eliminating $\mathrm{ChD}$ transmission as a health policy priority, in line with almost all Latin American initiatives in this regard (Moncayo 2003, Arnal et al. 2019).

\section{Acknowledgment}

The authors thank Dr. Juan Ignacio Arredondo Jimenez from the National Center for Epidemiological Survey and Prevention of the Secretary of Health (CENAVECE), Mexico, for his advice and support to obtain collaboration with local governments, Dr Felipe Lozano Kasten from the University of Guadalajara for his valuable support in the development of the central idea of the project, and the students from the Universities of Colima, Guadalajara and Nayarit, who performed most of the field work.

\section{Author Disclosure Statement}

No conflicting financial interests exist.

\section{Funding Information}

This project was financed by the fund, Fondo Regional para el Desarrollo de la Ciencia y Tecnologia (FORDECYT) del Consejo Nacional de Ciencia y Tecnologia de Mexico (CONACYT), number: FORDECYT 2009-01: 117535.

\section{References}

Alvarez-Hernandez DA, Franyuti Kelly GA, Diaz-Lopez-Silva R, González-Chávez AM, et al. Chagas disease: Current perspectives on a forgotten disease. Rev Med Hosp Gen Méx 2018; 81:154-164.

Antas PR, Medrano-Mercado N, Torrico F, Ugarte-Fernandez $\mathrm{R}$, et al. Early, intermediate, and late acute stages in Chagas' disease: A study combining anti-Galactose $\alpha-\operatorname{IgG}$, specific serodiagnosis, and Polymerase Chain Reaction analysis. Am J Trop Med Hyg 1999; 61:308-314.

Arnal A, Waleckx E, Rico-Chávez O, Herrera C, et al. Estimating the current burden of Chagas disease in Mexico:
A systematic review and meta-analysis of epidemiological surveys from 2006 to 2017. PLoS Negl Trop Dis 2019; 13: e0006859.

Benítez JA, Krisell-Contreras BA, Rivas M, Ramírez P, et al. Urban outbreak of acute orally acquired Chagas disease in Táchira, Venezuela. J Infect Dev Ctries 2013; 7:638-641.

Bethlem NM, LemleA, Saad EA. Pulmonary manifestations in Chagas' disease. In: Sharma OP, ed. Lung Disease in the Tropics. New York: Marcel Dekker, 1991; 251-277.

Carlier Y, Sosa-Estani S, Luquetti AO, Buekens P. Congenital Chagas disease: An update. Mem Inst O Cruz 2015; 110: 363-368.

Coll-Cárdenas R, Espinoza-Gómez F, Maldonado-Rodríguez A, Reyes-López PA, et al. Active transmission of human Chagas disease in Colima Mexico. Mem Inst O Cruz 2004; 99: 363-368.

Consejo Nacional de Poblacion (CONAPO). Indices de Marginación en México. Gobierno de México [Indices of Marginalization in Mexico. Government of Mexico.] Available at: http://www.conapo.gob.mx/es/CONAPO/Indices_de_Margina cion_2010_por_entidad_federativa_y_municipo

Diez M, Favaloro L, Bertolotti A, Burgos JM, et al. Usefulness of PCR strategies for early diagnosis of Chagas' disease reactivation and treatment follow-up in heart transplantation. Am J Transpl 2007; 7:1633-1640.

EPIDAT 3.1. Análise Epidemiolóxica de Datos. Versións 3.1. Xunta de Galicia. La Coruña, España: Dirección Xeral de Saúde Pública, 2012.

Gilber SR, Alban SM, Gobor L, de Oliveira-Bescrovaine J, et al. Comparison of conventional serology and PCR methods for the routine diagnosis of Trypanosoma cruzi infection. Rev Soc Bras Med Trop 2013; 46:310-315.

Gomes YM, Lorena VM, Luquetti AO. Diagnosis of Chagas disease: What has been achieved? What remains to be done with regard to diagnosis and follow up studies? Mem Inst $\mathrm{O}$ Cruz 2009; 104:115-121.

INEGI. Encuesta Intercensal 2015. Instituto Nacional de Estadistica e Informatica, Mexico. Available at http://cuentame .inegi.org.mx/monografias/default.aspx?tema=me

Lemle A. Chagas disease, Letter to editor. Chest 1999; 115:906.

Martínez-Ibarra JA, Grant-Guillén Y, Morales-Corona ZY, HaroRodriguez S, et al. Importance of species of Triatominae (Heteroptera: Reduviidae) in risk of transmission of Trypanosoma cruzi in western Mexico. J Med Entomol 2008; 45:476-482.

Melnikov V, Velasco FF, Espinoza-Gómez F, Rodríguez FG, et al. Pathologic changes in lungs caused by Mexican isolates of Trypanosoma cruzi in the acute phase of infection in mice. Am J Trop Med Hyg 2005; 73:301-306.

Moncayo A. Chagas disease: Current epidemiological trends after the interruption of vectorial and transfusional transmission in the Southern Cone countries. Mem Inst O Cruz 2003; 98:577-591.

Newton-Sánchez OA, Espinoza-Gómez F, Melnikov V, Delgado-Enciso I, et al. Seroprevalencia y factores de riesgo a $T$. cruzi en Colima, México. Gac Med Mex 2017; 153:179-184.

NucleoSpin Tissue. Genomic DNA from tissue. User manual. Protocol-at-a-glance (Rev.13). Macherey-Nagel, Düren, Germany. Available at https://www.takarabio.com/assets/ documents/User\%20Manual/NucleoSpin\%20Tissue\%20Geno mic\%20DNA\%20Purification\%20User\%20Manual\%20(PT4 010-1)_Rev_13.pdf. Accesed July 2014.

Nunes MdC, Barbosa MdM, Brum VA, Rocha MO. Morphofunctional characteristics of the right ventricle in Chagas' dilated cardiomyopathy. Int J Cardiol 2004; 94:79-85. 
Pereira de Godoy JM, Batigália F. Bilateral pulmonary artery aneurysm associated with bilateral pulmonary thromboembolism, superior vena caval thrombosis, and Chagas' disease: A case report. Angiology 2000; 51:609-614.

Pérez-Molina JA, Molina I. Chagas disease, Seminar. Lancet 2018; 391:82-94.

Pinto Dias JC, Novaes-Ramos A, Dias-Gontijo E, Luquetti A, et al. 2nd Brazilian consensus on Chagas disease 2015. Rev Soc Bras Med Trop 2016; 49:Suppl I:3-60.

Ramsey JM, Townsend Peterson A, Carmona-Castro O, MooLlanes DA, et al. Atlas of Mexican Triatominae (Reduviidae: Hemiptera) and vector transmission of Chagas disease. Mem Inst O Cruz 2015; 110:339-352.

Rassi A, Rassi A, Marin-Neto JA. Chagas disease, Seminar. Lancet 2010; 375:1388-1402.

Schijman AG, Bisio M, Orellana L, Sued M, et al. (2011) International study to evaluate PCR methods for detection of Trypanosoma cruzi DNA in blood samples from Chagas disease patients. PLoS Negl Trop Dis 2011; 5:e931.

Schijman AG, Vigliano C, Burgos J, Favaloro R, et al. Early diagnosis of recurrence of trypanosoma cruzi infection by polymerase chain reaction after heart transplantation of a chronic chagas' heart disease patient. J Heart Lung Transp 2000; 19:1114-1117.

Secretaria de Salud, Gobierno de Mexico. 2012. Anuario de morbilidad estatal 1998-2014. Available at www.epidemiol ogia.salud.gob.mx/anuario/html/morbilidad_estatal.html

Secretaria de Salud/Subsecretaría de Prevención y Promoción a la Salud. 2019. Manual de procedimientos para la enfermedad de Chagas en México. Secretaria de Salud, Gobierno de Mexico. Available at: https://www.gob.mx/cms/uploads/attachment/file/ 447946/Manual_de_Procedimientos_para_la_Enfermedad_de_ Chagas_en_Mexico.pdf

Shikanai-Yasuda MA, Barbosa-Carvalho N. Oral transmission of Chagas disease. Clin Infects Dis 2012; 54:845-852.
Singh W, Cruz LSH. Yaghmour B. Chagas disease and pulmonary hypertension. Am J Resp Critic Care Med 2019; 199:A3611.

Stimpert KK, Montgomery SP. Physician awareness of Chagas disease, USA. Emerg Infect Dis 2010; 16:871-872.

SUIVE/DGE/. Secretaría de Salud/Estados Unidos Mexicanos. BoletínEpidemiológico. Sistema Nacional de Vigilancia Epidemiológica Sistema Único de Información. 2018 semana 52. Aavilable at: https://www.gob.mx/cms/uploads/attach ment/file/425972/sem52.pdf

WHO/SIGN. Carpeta de material sobre seguridad de las inyecciones y los procedimientos conexos. WHO, Geneve. Swuitz. 2011. Pp 13-29. Available at: https://apps.who.int/ iris/bitstream/handle/10665/75247/9789243599250_spa.pdf; jsessionid=50C16AA05B88CF3F8330CAC68C48B58F?sequ ence $=1$

Wincker P, Telleria J, Bosseno MF, Cardoso MA. PCR-based diagnosis for Chagas' disease in Bolivian children living in an active transmission area: Comparison with conventional serological and parasitological diagnosis. Parasitology 1997; 114:367-373.

Yeoa M, Acosta N, Llewellyn M, Sánchez H, et al. Origins of Chagas disease: Didelphis species are natural hosts of Trypanosoma cruzi I and armadillos hosts of Trypanosoma cruzi II, including hybrids. Int J Parasitol 2005; 35:225-233.

Address correspondence to:

Francisco Espinoza-Gomez Laboratory of Public Health

Facultad de Medicina de la Universidad de Colima

Avenida Universidad 333 colonia Las Viboras, Colima

Colima 28040

México

E-mail: fespin@ucol.mx 